\title{
1512 en adelante: despuntar de los Derechos Humanos de los Amerindios iberoamericanos y las interacciones con la Comunicación
}

\author{
Estelle YSNEL \\ Universitat Jaume I \\ eysnel@yahoo.fr
}

\begin{abstract}
Resumen:
1542 : Descubrimiento de un Mundo Nuevo, choque de suma violencia entre los pueblos de ambos Continentes. La condición de los Indios conmueve a los Reyes Católicos. Las Leyes de Burgos promulgadas en 1512 son la primera legislación a favor de los Indios. El control de la aplicación de las Leyes resulta imposible por las difíciles comunicaciones entre ambos mundos. Bartolomé de Las Casas y Francisco de Vitoria, padres de los Derechos Humanos modernos contribuyen a la promulgación de las Leyes Nuevas. Hoy, las Constituciones definen los Derechos de los Indios. Se respetarán estos derechos?
\end{abstract}

Palabras claves : Comunicación; Derechos Humanos; Leyes de Burgos; Leyes Nuevas; Constituciones vigentes; Derecho Internacional

\section{From 1512 to present day : Birth of the Iberian Amerindians Human Rights and their interactions with Communication.}

\begin{abstract}
:
1492 : Discovery of a New World, extremely violent clash between the peoples of the two continents. The Catholic Kings were moved by the fate of the Indians. The Burgos Laws promulgated in 1512 are the first laws in the interests of the Indians. Controlling the legislation is made impossible by the difficulties in communicating between the two worlds. Bartolomé de Las Casas and Francisco de Vitoria, fathers of modern-day Human Rights, contribute to the promulgation of the New Laws. Today the Constitutions define the Rights of the Indians. Are these rights put in place and protected?
\end{abstract}

Key words : Communication; Human Rights; Burgos Laws; New Laws; Constitutions in force; International Law.

\section{Referencia normalizada:}

Ysnel, E. (2014): 1512 en adelante: despuntar de los Derechos Humanos de los Amerindios iberoamericanos y las interacciones con la comunicación. Historia y Comunicación Social. Vol. 19. Núm. Especial Marzo. Págs. 587-602.

Sumario : 1. Introducción. 2. Las Leyes de Burgos. 2.1. Los Amerindios como pueblo. 2.1.1. Los derechos no comunicacionales. 2.1.2. Los derechos comunicacionales. 2.2. Los Amerindios como individuos. 2.2.1. Los derechos no comunicacionales. 2.2.2. Los derechos comunicacionales 3. Las Leyes Nuevas. 4. La legislación vigente. 4.1. Los Amerindios como pueblo. 4.1.1. Los derechos no comunicacionales. 4.1.2. Los derechos comunicacionales. 4.2. Los Amerindios como individuos. 4.2.1. Los derechos no comunicacionales. 4.2.2. Los derechos comunicacionales. 5. Conclusiones. 


\section{Introducción}

El propósito de este artículo es presentar la evolución del estatuto de los Amerindios a través de sus derechos comunicacionales y no comunicacionales a partir de las Leyes de Burgos, Leyes Nuevas, Constituciones vigentes y normativa internacional.

En el siglo XV, no se habían descubierto aún todos los continentes conocidos hoy. Muchas de las tierras ya descubiertas permanecían incomunicadas a causa de barreras naturales. La Reconquista concluyó el 21 de enero de 1492 y se inició el tiempo de los descubrimientos y conquistas. Cristobal Colón consiguió convencer a la Reina Isabel la Católica que firmó las Capitulaciones de Santa Fe en abril de 1492. El 12 de octubre del mismo año, Cristobal Colón tocaba tierra creyendo haber alcanzado las Indias Occidentales.

Los descubrimientos fueron regidos por tres bulas alejandrinas : la bula intercaetera del 3 de mayo de 1493 apoyó a la Corona de Castilla otorgándole el título de Señores de ellas con pleno y libre y omnimoda potestad, autoridad y jurisdicción. La bula intercaetera del 4 de mayo de 1493 solucionó el conflicto de las fronteras con Portugal al diseñar una linea meridiana que había de pasar a 100 leguas al oeste de los Azores y de Cabo Verde. Al oeste de esta linea, las tierras pertenecerían a Castilla, al este a Portugal. La bula Dudum siquidem del 26 de septiembre de 1493 concedía a Castilla todas aquellas partes o regiones de las Indias descubiertas y ocupadas por nuestros capitanes. Al seguir los conflictos fronterizos entre Portugal y Castilla, se firmaron los dos tratados de Tordesillas el 24 de abril de 1494, el primero respecto al Atlántico, el segundo a África. En el Atlántico, se decidió que la linea entre ambos paises se situaría a 370 leguas al oeste de las islas de Cabo verde. Al oeste, las tierras serían de Castilla, al este de Portugal.

Tras el primer viaje de Cristobal Colón ya Almirante, Virrey y Gobernador General de las nuevas tierras, siguieron otros viajes. El Reino de Castilla autorizó nuevas expediciones para buscar el oro y especias todavia sin descubrir. El 16 de agosto de 1519, Hernán Cortés partió de Veracruz hacia Tenochtitlán. Dos años más tarde era dueño del Imperio Azteca. Entre 1523 y 1525 Alvarado conquistó la zona maya de Yucatán y Centroamérica. En 1531, Carlos V firmó las Capitulaciones de Toledo, Francisco Pizarro pudo salir de Panamá rumbo al Imperio Inca. En noviembre de 1532, conquistó Cuzco.

El Mundo Nuevo empezó a comunicarse con el Mundo Viejo por vias marítimas. La Conquista resultó un choque entre ambos mundos que engendró toda clase de violencias. El paraiso descrito por descubridores y conquistadores no tardó en volverse un infierno para los indios. 


\section{Las leyes de Burgos}

Las Leyes de Burgos cuyo nombre original era Ordenanzas reales para el buen rregimiento y tratamiento de los Yndios fueron promulgadas el 27 de diciembre de 1512 por el Rey Fernando el Católico, Rey de Aragón y Regente de Castilla. Su fin era el buen rregimiento y tratamiento de los Yndios y el conosçimiento de nuestra fee que sería neçesaria para su salvaçión porque de su natural son ynclinados a oçosidad e malos visyos. A raiz de la convocatoria de la Junta de Burgos se encuentran unos Frailes dominicanos, el predicador Fray Antonio de Montesinos, misionero en la Española, Fray Pedro de Córdoba, superior de los Domínicos en la Española y Fray Matias de Paz, teólogo salmantino. Cabe señalar que misioneros y teólogos ambos participaron del reconocimiento de los Derechos Humanos de los Indios y de su libertad. Fue la meta de la primera comunidad misionera en el Mundo Nuevo.

Trataremos de sintetizar el contenido de las Leyes de Burgos organizándolas en torno al derecho de los Amerindios como pueblo y luego como individuos poniendo de relieve sus derechos no comunicacionales y comunicacionales.

\subsection{Los Amerindios como pueblo}

\subsubsection{Los derechos no comunicacionales}

Entre los derechos no comunicacionales de los Amerindios como pueblo, sólo se menciona en la ley primera su derecho a la tierra : alrededor del bohío en el que vivían recibían una parte de tierra donde hacer unos cultivos, entre otros algodón, maiz y criar unas gallinas. De todo ello podían gozar como cosa suya propia ... questa hazienda nos se les pueda vender ni quitar por persona ninguna. Pero, los Amerindios habían sido trasladados a las estancias de los Españoles y por consiguiente habían perdido las tierras que antes les pertenecían.

\subsubsection{Los derechos comunicacionales}

Entre los derechos comunicacionales de los Amerindios como pueblo hay que destacar el traslado de las poblaciones y la organización administrativa y social.

Respecto al traslado de poblaciones, la Ley Primera precisa : es nuestra determinaçion de mudar los Yndios y hazerles sus estançias juntas con las de los españoles. La ley segunda precisa que el traslado de Indios y Caciques tiene que hacerse sin daños ni violencia y con su consentimiento sean traydos muy a su boluntad e ni rreçiban pena en la mudança.

En cuanto a la organización administrativa y social, los Amerindios dependen de una encomienda. Los repartimientos y la encomienda resultan de la cédula de la Reina Isabel dictada en Medina del Campo el 20 de diciembre de 1503. El objetivo principal era una forma de contrato que podía transmitirse de una generación a otra. Las dos condiciones claves del contrato eran, según Juan Cruz Monje Santillana, 
primero Evangelizar al Indio ; segundo el español debía habitar en esos territorios a fin de prevenir injerencias en la soberanía española. Juan Cruz también insiste en que era un derecho exclusivo de la Corona española y que sólo podía hacerse a favor de los españoles en América. Ni los indios, ni los súbditos de otros paises podían ser beneficiarios de la encomienda. La ley treinta y cinco precisa que una encomienda ha de tener como máximo 150 indios y como mínimo 40.

En cierto modo las Leyes de Burgos toman en cuenta la organización social de los Amerindios acordando a los caciques y a sus hijos un trato particular como lo veremos en adelante a propósito de la cultura (leyes diecisiete y veintidos).

Los Amerindios estaban bajo control de los visitadores ellos mismos dependiendo al principio del Almirante Diego Colón cuyo pápel consistía en hacer cumplir las ordenanzas. Por encima de todos estaba Don Fernando, Rey de Aragón y Regente de Castilla. Había dos visitadores por pueblo, eran elegidos y nombrados por el Almirante y jueces. Se escogían entre los vecinos más antiguos del pueblo (ley treinta). Su pápel era controlar el trabajo y la cristianización. Tenían que hacer dos visitas al año (ley treinta y una) y hacer cumplir las ordenanzas (ley treinta y cuatro). Cada dos años, los visitadores estaban controlados por el Almirante que hacía un balance cuyo resultado se comunicaba al Rey (ley treinta y cuatro), especialmente el número de indios ya que los visitadores estaban obligados a escribir en un registro qué indios nacían y morían (ley veintitres). De no cumplir su pápel los visitadores sufrían castigos (ley veintinueve).

\subsection{Los Amerindios como individuos}

\subsubsection{Los Derechos no comunicacionales}

Entre los derechos no comunicacionales de los Amerindios como individuos hay que destacar la justicia y los derechos sociales : alojamiento, condiciones de trabajo, alimentación, salud y familia.

Nos extraña que la justicia previera penas sólo para los visitadores y encomendores que no respetaran estrictamente las ordenanzas. Al final de la mayoría de las leyes, se mencionan las dichas penas. Solían consistir en la entrega de pesos de oro o en quitarles indios. En cuanto a los indios, a menudo se precisa que es necesario tratarles con dulzura y nunca usar violencia.

Respecto al alojamiento, la ley primera otorga cuatro bohíos por cincuenta indios. La ley diecinueve indica que los indios deben tener una hamaca en que duerma continuamente e que no los consyentan dormir en el suelo como hasta aqui se a hecho la qual dicha hamaca sean obligados a le dar dentro de doze meses primeros siguientes despues que tengan los dichos yndios señalados por rrepartimiento.

Dentro de las Leyes de Burgos, hay un cuidadoso enfoque hacia las condiciones de trabajo. La ley oncena prohibe hacer del indio una bestia de carga. La ley veinticuatro prohibe los castigos corporales así como nombres y motes despreciativos : ... ni 
personas algunas no sean osadas de palo ni açote ni llamar perro ni otro nombre a ningund yndio. Notamos que existía un deseo de respetar al indio. Los indios pertenecen a la encomienda de por vida. La ley veintiocho indica que, al morir el encomendero, si se vende la encomienda ha de ser con sus indios para que se queden en ella. Los indios trabajan en granjas y haciendas. Según la ley veinticinco, la tercera parte tiene que ir a las minas. La ley trece precisa el estatuto de los indios que trabajan en las fundiciones. Por cinco meses trabajados se les da cuarenta dias holgados. La ley dieciocho menciona que a ninguna muger preñada despues que pasare de quatro meses, no la enbien a las minas ni a hazer montones ... Tenían que servir en las casas e despues que parieren que su hijo fasta que sea de tres años sin que en todo este tiempo le manden yr a las minas ni hazer montones ni otra cosa en que la criatura rreçiba perjuyzio. La ley veintidos trata del estatuto peculiar de los sirvientes de caciques. Sólo hacen trabajos lígeros, reciben mejor comida y son adoctrinados para que puedan educar a los otros indios.

En lo que toca a la alimentación, la ley quince reconoce el derecho de los indios a estar bien alimentados pan e ajes e axi abasto e que a lo menos los domingos $e$ pasquas e fiestas les den sus ollas de carne gisada. A los mineros se les concede una libra de carne cada dia y quel dia que no fuere de carne le den pescado o sardinas.

Muy pocos datos tenemos acerca de la salud. La ley décima dice que el indio enfermo tiene derecho a la confesión y si muere se tiene que enterrar cristianamente.

A propósito de la familia, la ley dieciseis impone la monogamia : no deben tener mas de una muger. Se prohibe a los indios, especialmente a los caciques, que tomen mujer entre sus parientes. Tienen que casarse a ley y a bendiçion como lo manda la santa madre yglesia.

\subsubsection{Los derechos comunicacionales}

Entre los derechos comunicacionales de los Amerindios como individuos, las Leyes de Burgos sólo se interesan por los derechos culturales : tradiciones ancestrales, educación, religión.

Muy pocas informaciones tenemos acerca del respeto de las tradiciones ancestrales de los indios. La ley catorce sólo indica que los indios tienen derecho a llevar los areytos los domingos e fiestas como lo tienen por costumbre e asymesmo los dias de labor no dexando de trabajar por ello lo acostumbrado. La ley veinte trata de la ropa. Los indios reciben un peso de oro para comprar ropa pero no se precisa si es ropa tradicional o no. El cacique y su mujer tienen que ir mejor vestidos : los dichos casyques e sus mugeres es rrazon que anden mejor tratados e bestidos que los otros yndios. Lo único que se respeta dentro de la nueva organización social es la supremacia del cacique sobre los otros indios. Según la ley veintidos, el cacique tiene sirvientes cuyo número es proporcional al número de personas que tienen a cargo. Los hijos de los caciques tienen un trato especial como lo veremos al evocar de la educación. 
En lo que concierne la educación los hijos de caciques la ley diecisiete asegura que todos los hijos de los caçiques que ay en la dicha ysla y obiere de aqui adelante de hedad de treze años abajo se den a los frayles de la orden de san francisco ... porque los dichos frayles le muestren leer y escrevir y todas las otras cosas de nuestra fee ... para que los tales hijos de casyques muestren a los otros yndios. La ley novena dice que entre cincuenta indios, el encomendero tiene que elegir al muchacho más listo para que aprenda a leer y escribir, y también sepa de las cosas de nuestra fee para que aquel las muestre despues a los otros indios. La misma obligación existe para los muchachos indios que sirven de paje. Es interesante observar que esa educación se da para que se plante e arrayge nuestra santa fee catolica muy enteramente porque las animas de los dichos yndios se salven.

La religión constituye el meollo de las Leyes de Burgos. Hay que distinguir el papel del encomendero y el del clérigo. La primera obligación del encomendero es según la ley tercera les tener una casa para yglesia ... en la cual dicha iglesia pongan ymagenes de nuestra señora y una campanilla para los llamar a rrezar. El encomendero tiene que acompañar a sus indios y rezar con ellos. Es importante que lleguen a la iglesia descansados. La ley quinta obliga a los indios a oir misa a lo menos las pascuas e domingos e fiestas. De no haber iglesia en cada estancia, los encomenderos tienen que organizarse para reunir a los indios en una iglesia que sirva para varias estancias. Tienen la obligación de acompañarles a la ida y vuelta. La ley cuarta subraya la obligación de enseñar a los indios los diez mandamientos e syete pecados mortales e los articulos de la fee ... pero esto sea con mucho amor e dulçura. El papel educativo del encomendero es de primerísima importancia. En cuanto a los clérigos, tienen la obligación de acuerdo con la ley décima de confesar a los indios, por lo menos, una vez al año, con la ley doce, de bautizar a los recién nacidos a la primera semana de nacer, con la ley dieciseis de casar a los indios por la iglesia.

Las Leyes de Burgos son novedoras por las cincuenta copias impresas. Nunca se había hecho antes. Fueron pregonadas publicamente por las plaças e mercados e otros lugares acostumbrados desa dicha ysla por pregonero e ante escrivano publico. Eso muestra la importancia que el Rey Católico dió a la divulgación de las leyes que constituyen la primera legislación para los pueblos del Mundo Nuevo.

El Rey Fernando nos aparece sumamente moderno en su afán de comunicación. Desgraciadamente, por la gran distancia entre el Mundo Viejo y el Mundo Nuevo, lo largo de los viajes, la díficil información, siempre indirecta, del monarca, las Leyes de Burgos bien intencionadas hacia los súbditos indios resultaron un fracaso. Ya sabemos que dieron lugar a toda clase de abusos denunciados por los misioneros en las tierras conquistadas, sustituidos por los teólogos en España. Ambos fueron el eje de comunicación entre los dos mundos, haciendo de precursores de las O.N.G. y del Derecho Internacional. Entre ellos es imprescindible distinguir al dominico Fray Bartolomé de Las Casas que dedicó su vida entera a la defensa de los indios y que junto con el teólogo Fray Francisco de Vitoria, está al órigen de las Leyes Nuevas cuyo nombre original es Leyes y ordenanças nuevamente hechas por su Magestad 
para la gobernación de las Indias y buen tratamiento y conservación de los Indios promulgadas el 20 de noviembre de 1542 durante el reinado de Carlos I de España.

\section{Las leyes nuevas}

Llama la atención el propósito de Las Leyes Nuevas que reitera el de las Leyes de Burgos Nuestro principal yntento y voluntad siempre ha sido y es de la conservaçion y agmento de los yndios y que sean ynstruidos y enseñados en las cosas de nuestra sancta Fee Catholica y bien tratados como personas libres y vasallos nuestros como lo son ...

Dada la extensión y alejamiento de las tierras conquistadas, y por el desorden que imperaba en Perú, resultaba imprescindible reformar la administración y gobernación para mayor eficacia. Las Leyes Nuevas reglamentan los nuevos descubrimientos y poblaciones. Primero, el descubridor toma posesión de la tierra en nombre de los reyes castellanos (Ley 33). Es responsable y tiene que estar acompañado por un religioso o más (Ley 33). Se precisa que está rigurosamente prohibido esclavizar a los indígenas, ni coger nada a ellos contra su voluntad. Se permite la utilización de los nativos como intérpretes para así favorecer la penetración pacifica (Ley 34). El no respetar se castiga con pena de muerte.

Las Leyes Nuevas se interesan esencialmente por los derechos no comunicacionales de los Amerindios como individuo : derechos sociales en particular las condiciones de trabajo. Lo esencial es la reforma del régimen de la encomienda hacia su progresiva desapareción. Los repartimientos dados a los primeros conquistadores dejan de ser hereditarios y queda prohibido la concesión de nuevas encomiendas (Ley 30). Se prohibe la esclavitud. La Ley 21 declara abolida la esclavitud de los Indios ... los nativos son seres humanos libres y vasallos de la Corona Castellana. Se castigan los malos tratos y abusos de los encomenderos (Ley 29). Se precisan algunas condiciones de trabajo. Se prohibe que los Indios lleven cargas excepto si faltan animales o caminos, en ese caso, las faenas son voluntarias, nunca forzadas y sin menoscabo de la salud (Ley 24). En cuanto a las pesquerías de perlas no podrán realizarse con indios forzados bajo pena de muerte (Ley 25). También se cuida de que los servicios domésticos no se vuelvan una forma de esclavitud.

Al volverse libre, el indio está bajo la protección de las Audiencias que actúan en nombre del Rey. Deben ejercer la funcción amparadora de los naturales velando y celando el exacto cumplimiento de la legislación protectora (Leyes 19, 20, 23, 28, 31). El indio como vasallo tiene que pagar un tributo.

Es obvio señalar dentro de los derechos comunicacionales del individuo la justicia. Las Leyes Nuevas respetan los usos y costumbres de los Indios respecto de los indios y sus pleitos han de usarse procedimientos sumarios y ser juzgados conforme a sus usos y costumbres, siendo justas. 
Recordemos que la Reina Isabel la Católica mediante la Cédula del 20 de junio de 1500 ordenó liberar a los indios traidos y vendidos como esclavos en Castilla y les mandó volver al Mundo Nuevo como súbditos libres. Por lo tanto, queda demostrado que las leyes a favor de los Indios se aplicaban parcialmente o más bien no se aplicaban. Por eso, las Leyes Nuevas sublevaron una ola de protestas y rebeldías.

El afán de comunicación de las Leyes Nuevas se parece al de las Leyes de Burgos. Fueron publicadas y pregonadas en Sevilla, enviadas a las Indias. Lo nuevo radica en la traduccción a las lenguas indígenas por los religiosos. Así surge la voluntad de informar a la población indígena y comunicarse con ella.

Durante el reinado de Carlos II de España, se publicaron por Real Cédula del 18 de mayo de 1680 las Leyes de India conocidas como Recopilación de las Leyes de las Indias. Se trata de un balance de todas las leyes existentes y vigentes por el momento.

Hoy en día a las Leyes de Burgos, Leyes de Valladolid, Leyes Nuevas y Leyes de Indias se sustituyeron Constituciones y normativa internacional de Derechos Humanos que consideran a los Amerindios como cualquier ciudadano. No obstante, en la mayoría de las Constituciones hay artículos específicos relativos a los Amerindios.

\section{La legislación vigente}

Volveremos a tratar los derechos de los Indios evocados en las Leyes de Burgos siguiendo el mismo órden. Este breve balance cuyo propósito es mostrar qué es de la condición de los Amerindios unos quinientos años más tarde. Sólo nos basaremos en el Convenio 169 de la O.I.T. y Declaración de las Naciones Unidas sobre los Derechos de los Pueblos Indígenas así como en las Constituciones vigentes, limitándonos a los artículos específicos. Eligimos los paises cuyos pueblos descienden de las civilizaciones precolombinas : Aztecas en los Estados de Hidalgo, México, Michoacán, Morelos, Nayarit, Oaxaca, Puebla, San Luís Potosí, Tlaxcala y Veracruz en los Estados-Unidos Mexicanos y Nicaragua ; Mayas en los Estados de Campeche, Chiapas, Oaxaca, Quintana Roo, Tabasco y Yucatán en los Estados-Unidos Mexicanos, Guatemala y Honduras ; Incas en las Provincias Argentinas de Jujuy, Salta, Santiago del Estero y Tucumán, Bolivia, Colombia, Ecuador y Perú. También mencionamos a los guaranies aunque son selváticos : Provincias Argentinas de Corrientes, Chaco, Entre Ríos, Formosa, Jujuy, Misiones, Salta y Santa Fe, Bolivia, Ecuador y Paraguay.

\subsection{Los Amerindios como pueblo}

\subsubsection{Los derechos no comunicacionales}

Entre los derechos no comunicacionales de los Amerindios como pueblo, sólo trataremos de la tierra. Sin embargo, existen otros derechos como los derechos a los recursos naturales, al medio ambiente, al territorio así como los derechos económi- 
cos, inconcebibles en el siglo XVI. En Hidalgo, Michoacán, Nayarit, Quintana Roo, Guatemala, Honduras, Nicaragua, Colombia, Ecuador, Perú, Bolivia, Chaco, Entre Ríos, Formosa, Salta, Tucumán, Paraguay, el Convenio 169 y la Declaración reconocen y protegen la propiedad y posesión de sus tierras, entre otras, la forma colectiva o comunal. En Guatemala, Nicaragua, Perú, Bolivia, Chaco, Entre Ríos, el Convenio 169 y la Declaración, se insiste sobre la necesidad de otorgar tierras suficientes a los Amerindios cuando las necesiten. Por eso, en Guatemala hay una asístencia crediticia y técnica preferencial. En Nicaragua, se realiza merced a la reforma agraria. En Ecuador, Perú, Chaco, Entre Ríos y la Declaración se recure a la adjudicación. Tiene que hacerse gratuitamente en Ecuador, Chaco, Entre Ríos y Paraguay. En Michoacán, Nicaragua y Perú se insiste en el uso y disfrute de sus tierras. Las tierras son inalienables en Colombia, Ecuador, Bolivia, Formosa, Salta, Tucumán y el Convenio 169 ; imprescriptibles en Colombia, Ecuador, Perú, Bolivia, Chaco, Paraguay y el Convenio 169; inembargables en Colombia, Ecuador, Bolivia, Chaco y Paraguay ; indivisibles en Ecuador, Bolivia, Chaco, Entre Ríos y Paraguay ; irreversibles en Bolivia ; intransferibles en Chaco, Entre Ríos y Paraguay ; intransmisibles en Formosa, Salta y Tucumán; exentas de gravamen, tasas, impuestos o embargo en Ecuador, Bolivia, en Chaco, Formosa, Salta, Tucumán y Paraguay.

\subsubsection{Los derechos comunicacionales}

Entre los derechos comunicacionales de los Amerindios como pueblo, trataremos de los migrantes, del traslado de poblaciones y de la organización administrativa y social. Claro está, hoy en día, los Amerindios tienen derechos políticos : derecho a las elecciones, consulta, libre determinación y autonomía así como derecho a la libre circulación y cooperación fronteriza.

En Hidalgo, Michoacán, Morelos, Puebla, Quintana Roo, San Luís Potosí, Yucatán y el Convenio 169 se trata de la protección de los migrantes indígenas. Hay que proteger sus familias en Michoacán, Morelos y San Luís Potosí ; sus condiciones de trabajo en Hidalgo, Puebla, Quintana Roo y Puebla ; sus condiciones de salud especialmente de las mujeres en Hidalgo, Puebla y Quintana Roo ; la educación y nutrición de los menores en Hidalgo y Quintana Roo así como el respeto de sus derechos humanos y la difusión de su cultura en Hidalgo, Puebla, Quintana Roo e Yucatán. Todo ésto se aplica a los migrantes nacionales que se encuentran en el extranjero en Hidalgo, Puebla e Yucatán o a los migrantes extranjeros en Michoacán.

Teoricamente se prohiben los traslados de población salvo excepciones. En Oaxaca, se preven sanciones en caso de incumplimiento. El Paraguay, el Convenio 169 y la Declaración insisten en la necesidad de su consentimiento. El Convenio y la Declaración añaden la obligación de indemnización cuando exista daño y no sea posible la vuelta. En la Declaración, no se debe utilizar la fuerza. Guatemala permite el traslado fuera de la comunidad en materia laboral pero insiste en la interdicción de la desintegración de dicha comunidad y del pago de un salario no ajustado. 
En Campeche, Chiapas, Hidalgo, México, Michoacán, Nayarit, Oaxaca, Puebla, Quintana Roo, Tabasco, Tlaxcala, Veracruz, Guatemala, Nicaragua, Ecuador y Paraguay se trata de la organización social. En Campeche, Michoacán, Nayarit, Oaxaca, Niacaragua, Ecuador, Perú, Chaco, Santiago del Estero, Tucumán, el Convenio 169 y la Declaración se mencionan la organización administrativa, las formas de gobierno y sus instituciones. En Nayarit, Quintana Roo, Tabasco, Ecuador, Corrientes y Entre Ríos se evoca la convivencia y sus formas de vida.

\subsection{Los Amerindios como individuos}

\subsubsection{Los derechos no comunicacionales}

Entre los derechos no comunicacionales de los Amerindios como individuo sólo hablaremos de la justicia y los derechos sociales : alojamiento, condiciones de trabajo, alimentación, salud y familia. Claro está hoy en día los temas de la igualdad y prohibición de las discriminaciones son básicos. En Chiapas se garantiza una vida libre de violencia. En Oaxaca se castigan las conductas etnocidas. En Ecuador se afirma que la violación de estos derechos constituye delito de etnocidio. La Declaración prohibe la asimilación forzada y la destrucción de su cultura.

En cuanto a la justicia, en Hidalgo, Michoacán, Oaxaca, Puebla, San Luís Potosí, Yucatán, Perú, Chaco, Entre Ríos, Formosa, Salta, Tucumán se reconoce a los pueblos y o comunidades indígenas la personalidad juridíca. En Campeche, Chiapas, México, Hidalgo, Morelos, Oaxaca, Puebla, Quintana Roo, San Luís Potosí, Tabasco, Tlaxcala, Veracruz y Yucatán, se garantiza el acceso a la jurisdicción del Estado. En Campeche, Chiapas, Hidalgo, México, Michoacán, Morelos, Nayarit, Oaxaca, Puebla, Quintana Roo, San Luís Potosí, Tabasco, Veracruz, Yucatán, Ecuador, Perú, Bolivia, Paraguay, el Convenio 169 y la Declaración, hay que tomar en cuenta sus propios sistemas normativos en la regulación y solución de sus conflictos internos. Todo ésto deberá hacerse mediante sus autoridades tradicionales respetando las garantías individuales y sociales, los derechos humanos, la Constitución, las leyes, la dignidad e integridad de las mujeres o de los niños y mayores. Es necesario precisar los casos y procedimientos de validación por los jueces o tribunales correspondientes. Además, en cualquier juicio o procedimiento en que sea parte un indígena individual o colectivamente, cabe tomar en cuenta además su identidad, cosmovisión, cultura, tradiciones, prácticas, usos y costumbres. En Chiapas, Oaxaca, Quintana Roo, San Luís Potosí, Nicaragua, Colombia, Ecuador, Perú y Bolivia se instaura además una justicia indígena cuyos mecanismos de cooperación y coordinación con la justicia ordinaria conviene precisar. En Campeche, Chiapas, Hidalgo, Michoacán, Oaxaca, Puebla, Quintana Roo, San Luís Potosí, Tabasco, Yucatán, Nicaragua, Ecuador, Perú, Bolivia, Jujuy, Paraguay y el Convenio 169 el juicio debe llevarse a cabo en su lengua y cuando no sea posible, podrá ser asístido por intérpretes, traductores y defensores que hablen su lengua y conozcan su cultura. En Hidalgo, Nicaragua, Ecuador, Bolivia y Jujuy será gratuito. En Michoacán y Oaxaca se precisa que los jueces deben de conocer su idioma, su cultura y sus sistemas normativos. En Campeche y el Convenio 
169, siempre que sea posible, es mejor evitar la privación de libertad como sanción. En Chiapas, para favorecer la reintegración social de los indígenas, es mejor que compurgen sus penas lo más cerca posible de su comunidad.

A propósito de la vivienda, tiene que ser digna y decorosa en Chiapas. En Hidalgo, Quintana Roo y Tabasco se permite el acceso al financiamiento público y privado para la construcción y mejoramiento de las viviendas. En Morelos, San Luís Potosí y la Declaración, sólo se evoca el mejoramiento de las viviendas. En Puebla, los programas de desarrollo urbano y vivienda se realizan tomando en cuenta sus especificidades culturales. En Guatemala, la vivienda popular goza de protección especial del Estado y de asístencia crediticia y de técnica preferencial.

Por lo que es de las condiciones de trabajo, se menciona el empleo en México, el impulso del empleo en Puebla y el acceso al empleo en Ecuador y la Declaración. Se evocan también sus formas de organización del trabajo en Ecuador, su autonomía en el trabajo comunal en Perú y el acceso al trabajo en Bolivia y la Declaración. En el Convenio y la Declaración, se insiste sobre la igualdad de remuneración. El Convenio 169 añade el respeto de la seguridad e higiene en el trabajo, el otorgamiento de la seguridad social, el derecho de asociarse y sindicarse. También prohibe los trabajos peligrosos para su salud en particular como consecuencia de su exposición a plaguicidas o otras substancias tóxicas, los sistemas de contractación coercitiva incluidos todas las formas de servidumbre por deuda y el hostigamiento sexual. Se crean servicios adecuados de inspección del trabajo para averiguar el cumplimiento de todo ésto. La Declaración rehusa la explotación laboral de los menores.

En lo que concierne la alimentación, en Hidalgo, Puebla, Quintana Roo y Tabasco se insiste sobre la necesidad de apoyar la nutrición de los Amerindios mediante programas de alimentación sobre todo para los menores. El Ecuador insiste en el acceso a alimentos sanos en cantidad suficiente teniendo en cuenta sus peculiaridades culturales sobre todo de cultivo.

Respecto a la salud, en Campeche, Hidalgo, Michoacán, Morelos, Puebla, Quintana Roo, San Luís Potosí, Tabasco, Yucatán, Ecuador y Bolivia, el Convenio 169 y la Declaración se trata de la medicina tradicional. En Chiapas, México, Hidalgo, Michoacán, Morelos, Quintana Roo, San Luís Potosí, Tabasco, Yucatán Ecuador, Bolivia, el Convenio 169 y la Declaración se reconoce el acceso a los servicios de salud tomando en cuenta su cultura en Yucatán, Ecuador, Bolivia y el Convenio 169, su idioma en Yucatán y su cosmovisión y gratuidad en Bolivia. En Hidalgo, Morelos, Quintana Roo, San Luís Potosí, el Convenio 169 y la Declaración, es necesario ampliar la cobertura de los servicios sociales básicos.

Acerca de la familia, en Chiapas y Paraguay se trata del tema evocándolo respecto a la planificación familiar. En Nayarit y Oaxaca se evoca la necesidad de beneficiar del registro civil. En Bolivia se autoriza la identidad cultural junto a la ciudadanía en los documentos de identificación. En Chaco y Salta se necesitan registros especiales para los Amerindios. 


\subsubsection{Los derechos comunicacionales}

Entre los derechos comunicacionales de los Amerindios como individuo, sólo hablaremos de unos derechos culturales : tradiciones ancestrales, educación, religión. Cabe subrayar que hoy en día, los temas del estatuto de las lenguas indígenas, pluriculturalidad, artes, artesanias, folklore, patrimonio, turismo, ciencias, conocimientos, saberes ancestrales, propiedad intelectual, alfabetización mediática, medios de comunicación social respetando sus idiomas y culturas son básicos.

Para las tradiciones ancestrales, hay que reconocer, proteger y promover los usos y costumbres en Chiapas, México, Nayarit, Puebla, Tlaxcala y Veracruz; las tradiciones en Chiapas, Hidalgo, Nayarit, Tlaxcala, Guatemala, Entre Ríos, Formosa, Santiago del Estero, el Convenio 169 y la Declaración ; las costumbres en Guatemala, Nicaragua, Ecuador, Bolivia Formosa y el Convenio 169 y los vestidos indígenas en Guatemala, Ecuador, Bolivia y la Declaración.

En cuanto a la educación, se trata de la educación bilingüe en Campeche, Chiapas, México, Nayarit, Oaxaca, Tabasco, Tlaxcala, Veracruz, Guatemala, Colombia, Corrientes, Paraguay y el Convenio y de la educación bilingüe e pluricultural en Hidalgo, Michoacán, Morelos, Nayarit, Puebla, Quintana Roo, San Luís Potosí, Veracruz, Yucatán, Nicaragua, Ecuador, Perú, Bolivia, Chaco, Formosa, Salta, Tucumán y la Declaración. También se evoca el contenido de los programas en Chiapas, Hidalgo, Michoacán, Morelos, Nayarit, Oaxaca, Quintana Roo, Veracruz, Yucatán, Colombia, Ecuador, Bolivia, Chaco, Corrientes, Entre Ríos, Formosa, Paraguay y el Convenio 169. Se trata de la lucha contra el analfabetismo en Hidalgo, Morelos, Quintana Roo, Perú, Bolivia y Paraguay. Hay que favorecer la educación media superior y superior en Hidalgo, Morelos, Quintana Roo, Ecuador y Bolivia. Existen becas a todos los niveles en Hidalgo, Morelos, Quintana Roo. Se necesita una carrera docente digna en Ecuador y una formación docente en escuelas especiales en Bolivia.

Por lo que es de la religión, en Campeche, Bolivia y la Declaración hay que proteger los lugares sagrados. Se reconocen el pluralismo religioso en Chaco ; sus formas de expresión religiosa en Nayarit, Oaxaca, Puebla, Ecuador y la Declaración ; su religión en Tlaxcala ; sus religiones en Nicaragua ; sus creencias en Bolivia y Entre Ríos. Hidalgo se interesa por las actividades y productos materiales y espirituales. Ecuador, Bolivia, Tucumán y la Declaración mencionan la espiritualidad. Bolivia y la Declaración reconocen además la cosmovisión, los rituales, los mitos la libertad de religión, de conciencia y de fe así como la enseñanza de la religión. Perú insiste en el papel de la Iglesia Católica como elemento importante en la formación histórica, cultural y moral del país. En Perú y Bolivia, hay que respetar todas las confesiones y facilitar buenas relaciones entre ellas. La Declaración añade la posibilidad de obtener la repatriación de sus objetos de culto o restos humanos. 


\section{Conclusiones}

Del balance que acabamos de hacer, lo primero que llama la atención es la inversión del proceso iniciado en el siglo XVI cuando la Conquista reposaba en la codicia del oro y la evangelización de los pueblos conquistados. Es obvio que los Amerindios quedan profundamente marcados por la evangelización, pero la imposición de la religión católica no consiguió borrar los mitos, ritos y cosmovisión indios dando lugar al sincretismo religioso. Antaño las relaciones sociales se asentaban en un proceso de dominador a dominado. Hoy, las Constituciones y la normativa internacional intentan restituir al indio su tierra, identidad, cultura y lengua. El Derecho Natural en que se apoyaban Fray Bartolomé de Las Casas en su historia de las Indias y Fray Francisco de Vitoria en sus relecciones De Indis y De Iure Belli se ha convertido en los actuales Derechos Humanos. Por eso, los Amerindios pueden pretender a la libre determinación, autonomía y no discriminación. Sin embargo, si los Amerindios han recobrado su reconocimiento, no olvidemos que las actuales fronteras discrepan con las entidades culturales heredadas de la época precolombina creando una desigualdad de derechos entre ellos.

Entre las Leyes de Burgos y las Leyes Nuevas, los descubrimientos cambiaron la historia del mundo pero de los Reyes Católicos a Carlos I Emperador un mismo propósito : amparar a los Amerindios, educarles abriéndoles a la Fe Católica. Hoy en día las Constituciones y normativa internacional abogan por el respeto de los Amerindios. A pesar de ello, lo artificial de las áreas geográficas y los intereses económicos siguen contradiciendo las buenas intenciones de la legislación.

\section{Bibliografía}

\subsection{Libros:}

BEUCHOT Mauricio, los fundamentos de los derechos humanos en Bartolomé de Las Casas (primera edición, mayo 1994) : Editorial Anthropos, Barcelona CARRIERE Jean-Claude (1992) : la Controverse de Valladolid, le Pré aux Clercs GILLEN Charles (1995) : Bartolomé de Las Casas, une bibliographie, les éditions du CERF, Paris

HERNÁNDEZ MARTÍN Ramón (1998) : Francisco de Vitoria y su «relección sobre los Indios», los derechos de los hombres y de los pueblos, EDIBESA, Madrid

MURO OREJON Antonio, Las Leyes Nuevas de 15421543 : ordenanzas oara la gobernación de las Indias y buen tratamiento y conservación de los Indios, 1961, Sevilla, Universidad de Sevilla, Escuela de Estudios Hispanoamericanos, 2da edición corregida y aumentada con 50 fotograbados

de TUTELADA BUESO Juan Perez, LOPEZ OTO Emilio (1958) : Obras escogidas de Fray Bartolomé de LAS CASAS, Biblioteca de autores españoles, Madrid 
de TUTELADA BUESO Juan Perez, LOPEZ OTO Emilio (1961) : Obras escogidas de Fray Bartolomé de LAS CASAS, historia de Las Indias I, Biblioteca de autores españoles, Madrid

de TUTELADA BUESO Juan Perez, LOPEZ OTO Emilio (1961) : Obras escogidas de Fray Bartolomé de LAS CASAS, historia de Las Indias II, Biblioteca de autores españoles, Madrid

ZARAGOZA Gonzalo (noviembre 2011, octava edición) : América Latina Epoca Colonial, Anaya, Madrid

ZARAGOZA Gonzalo (septiembre 2009, décima edición) : Los grandes descubrimientos, Anaya, Madrid

6.2 Artículos en publicaciones web :

ALTAMIRA Rafael (Dec., 1938) : el texto de las Leyes de Burgos de 1512 en Revista de Historia de América, ${ }^{\circ} 4$ pp.5-79, publicado por Pan American Institute of Geography and History. Disponible en http://www.jstor.org/stable/20135913 Consultado el 17 de septiembre de 2013

MONJE SANTILLANA Juan Cruz, las Leyes de Burgos de 1512, precedente del derecho internacional y del reconocimiento de los derechos humanos. Disponible en http://dspace.ubu.es:8080/trabajosacademicos/bistream/10259.1/85/1/Monje Santillana.pdf Consultado el 17 de septiembre de 2013

Leyes y ordenanças nuevamente hechas por su Magestad pa la governacion de los Indios y buen tratamiento y conservacion http://www.europeana.eu/portal/record/9200127/8837B42FD65679CC4F7451931B2A505E38B77353.html?star$\mathrm{t}=1$ \&query $=$ leyes + de + indias\&startPage $=1$ \&rows $=24$

Constitución Política del Estado de Campeche del 29 de mayo de 1965 hasta las reformas del 13 de septiembre de 2012: Artículo 7

Constitución Política del Estado Libre y Soberano de Chiapas hasta las reformas del 13 de noviembre de 2012 : Artículos 3 XXVI 2 2, 4\$2, 7, 44 VI, 50 3 V, 57 \$ VI et $\S 10,58 \S 6 \mathrm{VI}$

Constitución Política del Estado de México de 1917 hasta las reformas del 11 de octubre de 2012 : Artículo 17

Constitución Política del Estado de Hidalgo del 1ro de octubre de 1920 hasta las reformas del 25 de febrero de 2013 : Artículo $5 \$ 8$ a $\$ 19$

Constitución Política del Estado Libre y Soberano de Michoacán de Ocampo de 1918 hasta las reformas del 28 de enero de 2013 : Artículos 3, 94\$4,103\$3, 139\$2 d)

Constitución Política del Estado Libre y Soberano de Morelos del 16 de noviembre de 1930 hasta las reformas del 10 de septiembre de 2012 : Artículo 2 bis

Constitución Política del Estado Libre y Soberano de Nayarit de 1918 hasta las reformas del 21 de enero de 2013 : Artículos 7 IV et XIII 4. d)

Constitución Política del Estado Libre y Soberano de Oaxaca del 4 de abril de 1922 hasta las reformas del 20 de junio de 2012 : Artículos 16, 112, $126 \S 4$ et $\S 5$

Constitución Política del Estado Libre y Soberano de Puebla del 2 de octubre de 1917 hasta las reformas del 19 de octubre de 2012 : Artículo 13 
Constitución Política del Estado Libre y Soberano de Quintana Roo hasta las reformas del 8 de marzo de 2013 : Artículos $13 \$ 6$ a $\$ 9$ A et $B$ y $97 \$ 5$

Constitución Política del Estado Libre y Soberano de San Luís Potosí del 5 de octubre de 1917 hasta las reformas del 6 de noviembre de 2010 : Artículos 9 y $18 \$ 3$

Constitución Política del Estado Libre y Soberano de Tabasco del 5 de abril de 1919 hasta las reformas del 26 de septiembre de 2012 : Artículo 2

Constitución Política del Estado Libre y Soberano de Tlaxcala hasta las reformas del 5 de diciembre de 2012 : Artículo $1 \$ 2$

Constitución Política del Estado Libre y Soberano de Veracruz de Ignacio de la Llave del 25 de septiembre de 1917 hasta las reformas del 9 de noviembre de 2012 Artículos 5 y $10 \$ 3 \mathrm{f}$ )

Constitución Política del Estado de Yucatán del 14 de enero de 1918 hasta las reformas del 31 de agosto de 2012 : Artículos $2 \$ 3$ a $\$ 11,7$ bis, 90 Apartado A II, 95 bis

Constitución Política de la República de Guatemala decretada por la Asamblea Nacional Constituyente el 31 de mayo de 1985, reformada por la Consulta Popular, Acuerdo Legislativo 18-93 del 17 de noviembre de 1993 : Preámbulo y artículos 66 a 69 y 76

Constitución Política de la República de Honduras del 11 de enero de 1982 (decreto $\mathrm{n}^{\circ} 131$ ) con las reformas del 20 de enero del 2006 (decreto $\mathrm{n}^{\circ} 381-2005$ ) : artículo 346

Constitución Política de la República de Nicaragua hasta la ley n ${ }^{\circ} 527$ del 8 de abril de 2005 de reforma parcial de la Constitución: Artículos 5, 33 2) 2.1. , $34 \$ 16$. , 89, 99, 103, 106, 107,121,164 13), 180

Constitución Política de la República de Colombia del 4 de julio de 1991 hasta las reformas del Acto legislativo 2 del 27 de diciembre de 2012 : Artículos 10, 68\$5, 246

Constitución Política de la República del Ecuador del 20 de octubre de 2008 con las reformas del 13 de julio de 2011 : Preámbulo, artículos 1, 25, 27, 29, 32, 45, 57, 76 7.f. et i. , 77 \$1 7. , 86 1. , 171, 281, 321, 329, 343, 347 9., 350, 358, 360, 3634.

Constitución Política de la República de Perú del 29 de diciembre de 1993 hasta las reformas de la Ley $\mathrm{N}^{\circ} 28.607$ del 4 de octubre de 2005 : Artículos 2 19.\$2, 15ई2, $17 \$ 4,88,89,149$

Constitución de la República de Bolivia de 24 de enero de 2009 : Preámbulo, artículos 1, 4, 9 2., 17, 18 III., 30, 31, 35 II., 42, 45 II., 54 III., 78 II., 79, 80 II., 83, 84, 86, 90, 91, 93 IV. et V., 95, 96 I., 98, 100 I., 103 III., 119 I., 120 II., 178 i., 179, 186, 187, 190, 191, 192, 197 I., 199 II., 202 8. et 11., 206 II. et V., 218 II., 394 I. et III., 395 I., 397 II.

Constitución de la Provincia del Chaco del 26 de octubre de 1994 : Preámbulo, artículos 37, 42 3)

Constitución de la Provincia de Corrientes del 8 de junio de 2007 : Artículos 58\$2, 66, 204

Constitución de la Provincia de Entre Ríos del 3 de octubre de 2008 : Artículos 26, 33, 260 
Constitución de la Provincia de Formosa del 8 de julio de 2003 : Artículos 79, 92§1, 93 10)

Constitución de la Provincia de Jujuy del 22 de octubre de 1986 : Artículo 29 5. A)

Constitución de la Provincia de Salta del 2 de junio de 1986 con las reformas del 7 de abril de 1998 : Artículo 15

Constitución de Santiago del Estero del 26 de noviembre de 2005 : Preámbulo

Constitución de la Provincia de Tucumán : Artículo 149

Constitución de la República del Paraguay del 20 de junio de 1992 : Artículos 124 ., $63,64,66,73,77$

Convenio 169 sobre pueblos indígenas y tribales en países independientes del 27 de junio de 1989

Declaración de las Naciones Unidas sobre los derechos de los pueblos indígenas del 10 de diciembre de 2007

Encyclopédie.snyke.com, Las Leyes Nuevas. Disponible en http://encyclopedie-es. snyke.com/articles/leyes_nuevas.htlm Consultado el 17 de septiembre de 2013

Julio y Alexandru, las Leyes de Indias. Disponible en http://julioyalexandru.blogspot. fr/2012/01/leyes-de-india.html Consultado el 17 de septiembre de 2013

Wikipedia, Las Leyes de Burgos. Disponible en http://es.wikipedia.org/wiki/Leyes de_Burgos Consultado el 17 de septiembre de 2013

Wikipedia, Las Leyes Nuevas. Disponible en http://es.wikipedia.org/wiki/Leyes Nuevas Consultado el 17 de septiembre de 2013

Wikipedia, Las Leyes de Indias. Disponible en http://es.wikipedia.org/wiki/Leyes de_Indias Consultado el 17 de septiembre de 2013

\section{La autora}

Estelle Ysnel.

1996: Licenciatura en Derecho, Facultad de Derecho, Ciencias Económicas y Gestión, Universidad de Rouen (Francia)

1999: Maestria en Derecho de los Paises de la Comunidad Europea, Facultad de Derecho, Universidad Complutense de Madrid (Programa Erasmus). Tema: La Organización administrativa en Francia y España Director: el Catedrático Iñigo MARTINEZ DE PISÓN APARICIO

2000: D.E.A. (Diploma de Estudios Especializados) en Derecho internacional y europeo, Facultad de Derecho, Ciencias Económicas y Gestión, Universidad de Rouen (Francia). Tema: El estatuto de los Amerindios Iberoamericanos y el Derecho internacional, Director: el Profesor Emerito Raymond GOY

2012: Doctoranda Universitat Jaume I de Castellón. Tema de la tesis europea: Los Amerindios en Iberoamérica: interacciones entre Comunicación y Derechos Humanos. Directora: la Doctora Estela BERNAD MONFERRER 